\title{
Some applications of viscometry from studies on the absorption of vegetable oils and solvents by paper substrates
}

\author{
G. H. Hutchinson, J. W. Davison
}

(C) FSCT and OCCA 2008

\section{Erratum to: J. Coat. Technol. Res. DOI 10.1007/s11998-008-9083-y}

The original version of this article unfortunately contained two mistakes.

The first sentence of the section "Comparative oxidation with a drying oil" mistakenly used the word "linolenic" twice. The second occurrence of this word should have been "linoleic". The correct sentence is given below.
The online version of the original article can be found under doi:10.1007/s11998-008-9083-y.

G. H. Hutchinson (凶)

19 Broadlands Avenue, Southbourne,

Dorset BH64 4Q, UK

e-mail: WallisSciences@aol.com

J. W. Davison

Davison Chemographics, Unit 28, Borden, Hampshire

GU35 9QF, UK

e-mail: John@davchemo.demon.co.uk
The "linolenic"-rich linseed oil is a drying oil; whereas SFO, a "linoleic"-rich oil of lower iodine value (Table 4), is a semi drying oil with much inferior film-forming properties.

The caption for Fig. 11 was incorrect. The corrected caption is given below.

Fig. 11: Calibration of $m$ vs $\sqrt{\frac{1}{2 \eta}}$. Thermally oxidized sunflower seed oils, Whatman WH41 filter paper, $20^{\circ} \mathrm{C}$. 